\title{
Characteristic photon yields from thermal neutron activation of explosives for a portable detection system
}

\author{
H Khan ${ }^{1 *}$, ZU Koreshi', SR Sheikh ${ }^{2}$ and MY Khan ${ }^{3}$ \\ ${ }^{1}$ Department of Sciences and Humanities, National University of Computer and Emerging Sciences, Islamabad, Pakistan. \\ ${ }^{2}$ Department of Mechatronics Engineering, Air University, Islamabad, Pakistan. \\ ${ }^{3}$ Department of Mathematics and Statistics, Riphah International University, Islamabad, Pakistan.
}

Submitted: 05 August 2019; Revised: 29 October 2020; Accepted: 22 January 2021

\begin{abstract}
Explosive detection systems (EDS) based on thermal neutron activation can be used for detection and identification of concealed explosives such as trinitrotoluene, cyclonite, and ammonium nitrate $\left(\mathrm{NH}_{4} \mathrm{NO}_{3}\right)$. Activation results in emission of characteristic gamma rays of constituents whose relative intensities yield atomic fractions of the explosives and instant identification. Applications of EDS can also be at airports and seaports as well as in vehicles. Such systems have been studied, developed and tested and are being refined in their design and functionality as several issues still need to be resolved, such as the associated high radiation dose and development of fast algorithms for their identification. This paper considers a portable EDS, incorporating a neutron source and radiation detection systems, which can fit into a portable briefcase of dimensions $40 \mathrm{~cm} \times 30 \mathrm{~cm} \times 8 \mathrm{~cm}$. The detection efficiency and radiation dose are computed by carrying out simulations, to estimate the strengths of characteristic photon yields, using the Monte Carlo code MCNP5 to present a useful and efficient engineering design. Two factors of concern were found to be the excessive photons from material of least interest $\left({ }^{10} \mathrm{~B}, \mathrm{Ca}\right.$, $\mathrm{Pb}$ ) and the excessive radiation dose in the immediate vicinity of a portable system. However, an accurate estimate of the $\mathrm{H} / \mathrm{N}$ ratio was obtained with simulation carried out for $\sim 1 \mathrm{~kg}$ concealed TNT explosive. The ratio was found to be $\sim 1.61$ which is very close to the actual ratio (1.67). Thus, the accurate identification of TNT explosives can be efficiently carried out by such a portable system.
\end{abstract}

Keywords: Explosive detection system, engineering design, MCNP thermal neutron activation.

\section{INTRODUCTION}

Explosive detection systems (EDS) based on thermal neutron activation (TNA) depend on the quality of signatures of characteristic photons for their detection and characterization (Kuznetsov \& Osetrov, 2006; Koltick \& McConchie, 2007; Lanza, 2007; Whetstone $\&$ Kearfott, 2014). Both prompt- and thermal activation analyses have been investigated for the detection of concealed explosives in luggage, vehicles, air cargo and for humanitarian demining. With over 110 million antipersonnel mines in 64 countries, according to the United Nations' estimates, more than 26,000 people a year become victims. It is thus important to carry out studies which can lead to the design of useful field portable explosive detection systems. Potential neutron sources for such portable systems have been studied and found to show satisfactory performance for gamma neutron activation applications (Naqvi et al., 2014). Such studies with simulation codes, as well as experiments towards practical and efficient EDS have demonstrated the applicability of neutron activation to obtain signatures and identify explosives.

For simulation of coupled neutron-gamma transport, the Monte Carlo code MCNP (Maučec \& De Meijer, 2002; Team, 2003; Baysoy \& Subaş1, 2013) has been

\footnotetext{
*Corresponding author (hamda.khan@nu.edu.pk; (iD https://orcid.org/0000-0001-7673-2097)
} 
extensively used and is regarded as a reliable tool for the design of nuclear systems (Uchai et al., 2008). This paper, based on the knowledge of design sensitivity leading to optimisation of EDS components (Koreshi \& Khan, 2016, 2017; Khan et al., 2017) considers a portable EDS incorporating a neutron source and detection systems, which fits into a common briefcase of dimension $40 \mathrm{~cm} \times 30 \mathrm{~cm} \times 8 \mathrm{~cm}$. The detection efficiency and radiation dose are computed using the Monte Carlo code MCNP5 to present a useful and efficient portable design.

From the simulation, the element number ratios for an unknown sample $[\mathrm{H}] /[\mathrm{N}]$ and $[\mathrm{C}] /[\mathrm{N}]$ can be estimated. The ratios $[\mathrm{H}] /[\mathrm{N}]$ for explosives is: TNT $\left(\mathrm{C}_{7} \mathrm{H}_{5} \mathrm{~N}_{3} \mathrm{O}_{6}\right)$ 1.67, $\mathrm{RDX}\left(\mathrm{C}_{3} \mathrm{H}_{6} \mathrm{~N}_{6} \mathrm{O}_{6}\right)$ 1, Nitroglycerine $\left(\mathrm{C}_{3} \mathrm{H}_{5} \mathrm{~N}_{3} \mathrm{O}_{9}\right) 1.67$ while for common materials such as nylon $\left(\mathrm{C}_{6} \mathrm{H}_{13} \mathrm{NO}\right)$ it is 13 . Drugs such as cocaine, heroin, and morphine have very high ratios in the range 19-23.

\section{METHODOLOGY}

Figure 1 shows the model of the 'Briefcase EDS' for a landmine detector considered in this work. A point source $\mathrm{S}$ is encapsulated in a shielded cylindrical shell facing the soil with concealed explosive. On the sides of the source, is the neutron detection system with $\mathrm{BF}_{3}$ detectors, and below and above the source are the sodium iodide (NaI) scintillation detectors for gamma detection from backscattered radiation.

Material compositions used in the simulation are listed in Table 1.

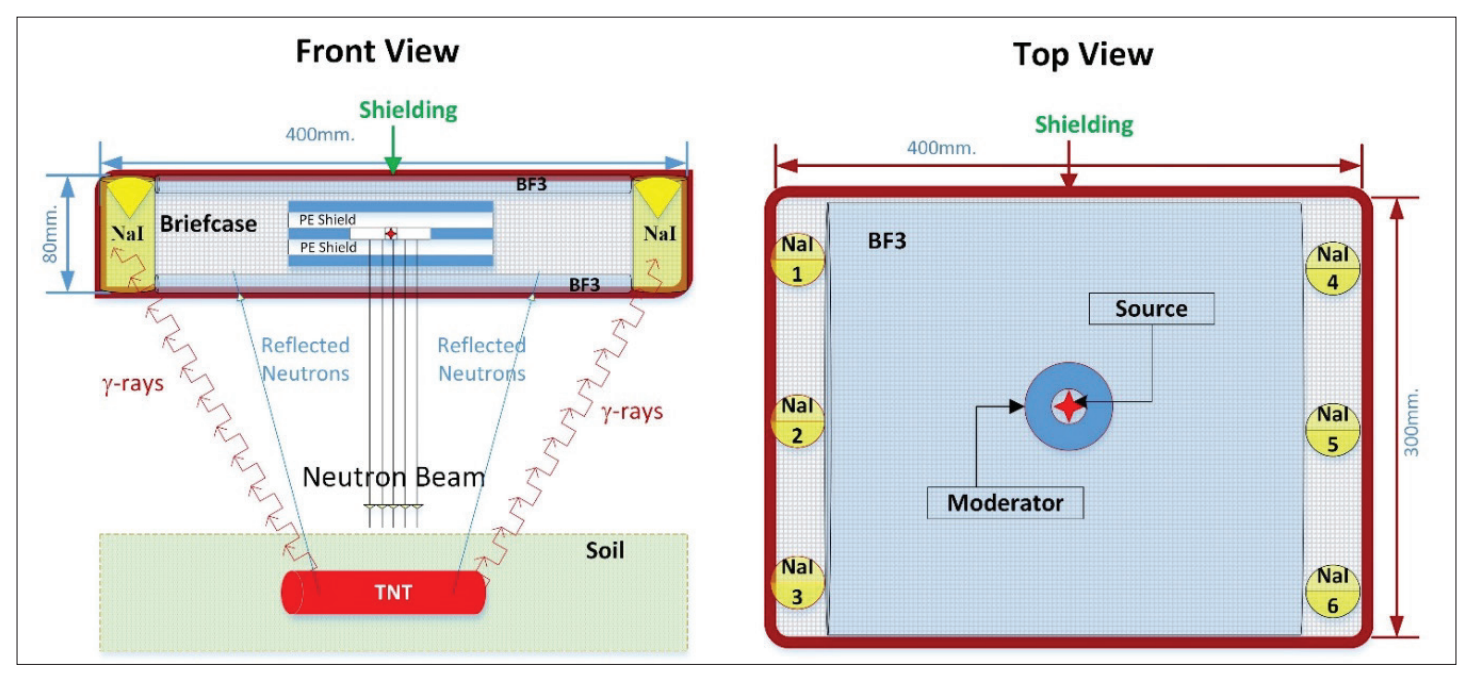

Figure 1: Model of briefcase EDS placed above soil with concealed TNT explosive

Table 1: Material compositions

\begin{tabular}{lccccc}
\hline Material & $\left(\mathrm{g} / \mathrm{cm}^{3}\right)$ & \multicolumn{4}{c}{ Element and (mass fraction) } \\
\hline Dry Air & 0.001200 & ${ }_{7}^{14} N 0.75519$ & ${ }_{8}^{16} \mathrm{O} 0.23179$ & ${ }_{6}^{12} \mathrm{C} .000140$ & ${ }_{18}^{40} \mathrm{Ar} .0129$ \\
Wax & 0.930000 & ${ }_{1}^{1} \mathrm{H} 0.148605$ & ${ }_{6}^{12} \mathrm{C} 0.85139$ & - & - \\
Soil: Limestone & 2.710000 & ${ }_{6}^{12} \mathrm{C} 0.12$ & ${ }_{8}^{16} \mathrm{O} 0.48000$ & ${ }_{20}^{40} \mathrm{Ca} 0.40000$ & - \\
$\mathrm{BF}_{3}$ & 0.002567 & ${ }_{5}^{10} \mathrm{~B} .143368$ & ${ }_{5}^{11} \mathrm{~B} 6.568 \mathrm{e}-3$ & ${ }_{9}^{19} F 0.850064$ & - \\
$\mathrm{TNT}$ & 1.654000 & ${ }_{1}^{1} \mathrm{H} 0.022189$ & ${ }_{6}^{12} \mathrm{C} 0.37016$ & ${ }_{7}^{14} \mathrm{~N} 0.18500$ & ${ }_{8}^{16} \mathrm{O} .4230$ \\
\hline
\end{tabular}




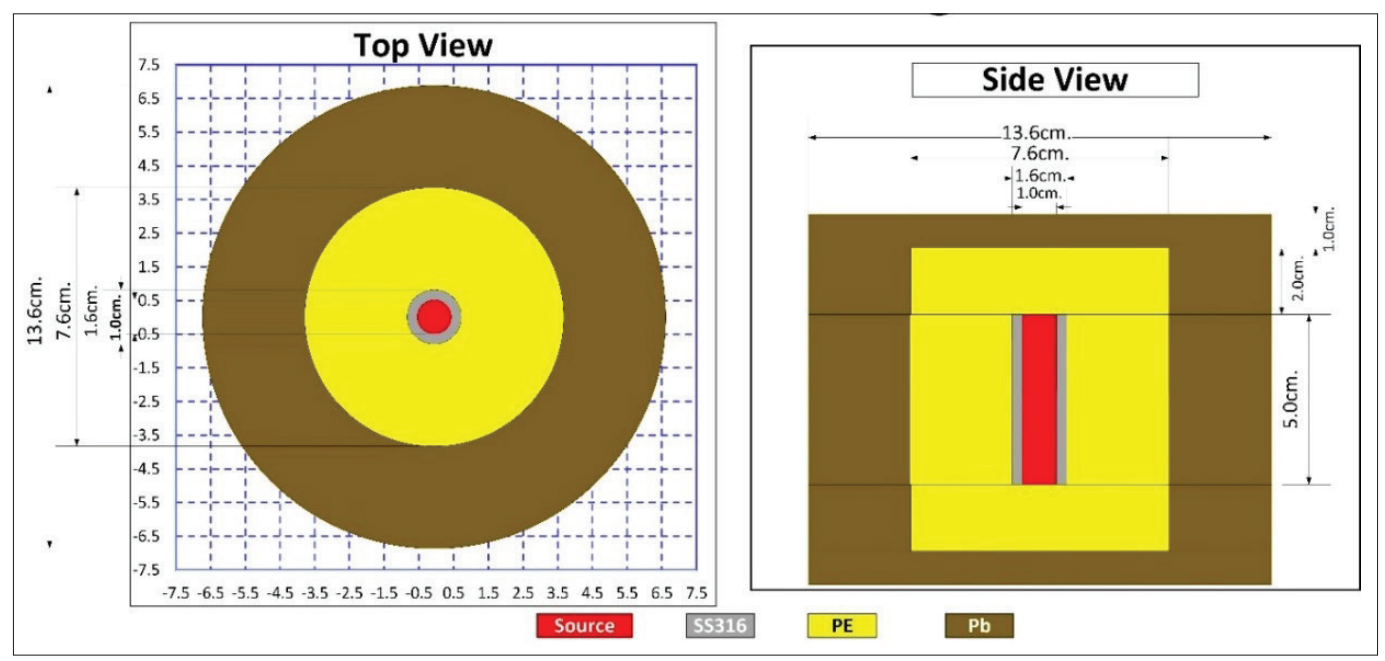

Figure 2: $\quad$ The source and its shielding $(\mathrm{red}=$ source, grey $=\mathrm{SS} 316$, yellow $=$ polyethylene, brown $=$ lead $)$

Table 2: $\quad$ Source properties of $\mathrm{Am}-\mathrm{Be}$ and ${ }^{252} \mathrm{Cf}$

\begin{tabular}{lll}
\hline Source & Am-Be & ${ }^{252} \mathrm{Cf}$ \\
\hline Type & $\alpha$-emitter & spontaneous \\
Half-life (years) & 432.2 & 2.645 \\
Specific activity $(\mathrm{Ci} / \mathrm{g})$ & - & 532 \\
Neutron yield $\left(\mathrm{n} \mathrm{s}^{-1} \mathrm{Ci}^{-1}\right)$ & $2-2.4 \times 10^{6}$ & $4.4 \times 10^{9}$ \\
Average energy $(\mathrm{MeV})$ & $\sim 4.2 \mathrm{MeV}$ & $\sim 2$ \\
Maximum energy $(\mathrm{MeV})$ & $\sim 11 \mathrm{MeV}$ & $\sim 10$ \\
Neutron dose & $0.59-0.73 \mathrm{~Sv} \mathrm{~h}^{-1}$ at $1 \mathrm{~m} / \mathrm{GBq}$ & $22-23 \mathrm{~Sv} \mathrm{~m}^{2} \mathrm{~g}^{-1} \mathrm{~h}^{-1}$ \\
Gamma dose & $0.68 \mathrm{~Sv} \mathrm{~h}^{-1}$ at $1 \mathrm{~m} / \mathrm{GBq}$ & $1.6 \mathrm{~Sv} \mathrm{~m}^{2} \mathrm{~g}^{-1} \mathrm{~h}^{-1}$ \\
\hline
\end{tabular}

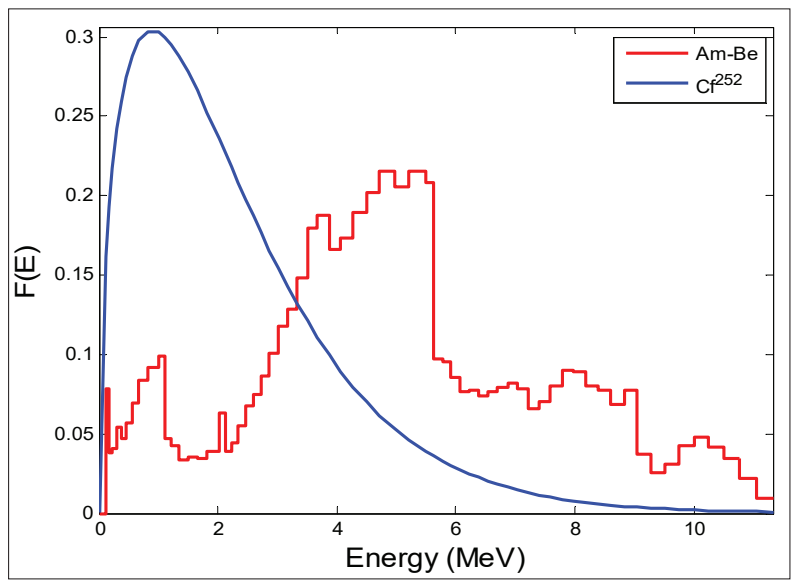

Figure 3: $\quad$ Energy spectra of ${ }^{252} \mathrm{Cf}$ and $\mathrm{Am}-\mathrm{Be}$ sources

\section{Source}

An encapsulated point source is considered as shown in Figure 2 (seen from the top and side) placed in a cylindrical chamber $0.5 \mathrm{~cm}$ radius and height $0.5 \mathrm{~cm}$. The source casing is a steel (SS316) cylinder of thickness $0.3 \mathrm{~cm}$ surrounded by $3 \mathrm{~cm}$ layers of borated polyethylene and lead. On the top and bottom, the shielding consists of layers of $2 \mathrm{~cm}$ polyethylene followed by $1 \mathrm{~cm}$ lead.

Simulations were carried out for two neutron sources, namely, californium ${ }^{252} \mathrm{Cf}$ and AmericiumBeryllium (Am-Be) with properties given in Table 2 and energy spectra shown in Figure 3. In MCNP, the Watt spectrum is used for modelling ${ }^{252} \mathrm{Cf}$. Energy distribution is modelled with a probability distribution function, $f(E)=C e^{-E / a} \sinh \sqrt{b E},(\mathrm{a}=1.025, \mathrm{~b}=2.926)$ while for $\mathrm{Am}-\mathrm{Be}$ a discrete distribution is used. 
Table 3: Materials for neutron radiation shielding (weight fractions)

\begin{tabular}{llllllll}
\hline Element & $\begin{array}{l}\text { Material } \\
\text { ID }\end{array}$ & PE & wax & B-paraffin & BPE-5 & BPE-30 & B ${ }_{4} \mathrm{C}$ \\
& & & & & & & \\
\hline $\mathrm{H}$ & $1001.66 \mathrm{c}$ & 0.1400 & 0.1486 & 0.1400 & 0.1160 & 0.0870 & - \\
${ }^{10} \mathrm{~B}$ & $5010.66 \mathrm{c}$ & - & - & 0.0100 & 0.0100 & 0.0600 & 0.1557 \\
${ }^{11} \mathrm{~B}$ & $5011.66 \mathrm{c}$ & - & - & 0.0200 & 0.0400 & 0.2400 & 0.6269 \\
$\mathrm{C}$ & $6000.66 \mathrm{c}$ & 0.8600 & 0.8514 & 0.8300 & 0.6120 & 0.6130 & 0.2174 \\
$\mathrm{O}$ & $8016.66 \mathrm{c}$ & - & - & - & 0.2220 & - & - \\
Total & & 1.00 & 1.00 & 1.00 & 1.00 & 1.00 & 1.00 \\
Density $\left(\mathrm{g} \mathrm{cm}^{-3}\right)$ & 0.9200 & 0.9300 & 0.9470 & 1.0800 & 1.1900 & 2.5200 \\
\hline
\end{tabular}

Table 4: Materials for photon radiation shielding (weight fractions)

\begin{tabular}{lccc}
\hline Element & Material ID & SS316 & $\mathrm{Pb}$ \\
\hline $\mathrm{Si}$ & 14000 & 0.0100 & - \\
$\mathrm{Cr}$ & 24000 & 0.1700 & - \\
$\mathrm{Mn}$ & 25055 & 0.0200 & - \\
$\mathrm{Fe}$ & 26000 & 0.6550 & - \\
$\mathrm{Ni}$ & 28000 & 0.1200 & - \\
$\mathrm{Mo}$ & 42000 & 0.0250 & - \\
$\mathrm{Pb}$ & 82000 & - & 1.0000 \\
Total & & 1.0000 & 1.0000 \\
Density $\left(\mathrm{g} \mathrm{cm}^{-3}\right)$ & & 7.92 & 11.35 \\
\hline
\end{tabular}

\section{Detection system}

The explosive, trinitrotoluene (TNT: $\mathrm{C}_{7} \mathrm{H}_{5} \mathrm{~N}_{3} \mathrm{O}_{6}$ ), placed in a cylinder of radius $10 \mathrm{~cm}$ and height $2 \mathrm{~cm}$ located vertically below the ground with its upper surface at a depth of $1 \mathrm{~cm}$, weighs $1.039 \mathrm{~kg}$. For the neutron detection system, a $\mathrm{BF}_{3}$ detection system is modelled with gas filled at 1 atm (density $0.002567 \mathrm{~g} \mathrm{~cm}^{-3}$ ). Surrounding the $\mathrm{BF}_{3}$ system is a polyethylene moderator (density $0.93 \mathrm{~g} \mathrm{~cm}^{-3}$ ) for thermalising source neutrons. For radiation shielding, the materials considered for neutrons and photons in the simulation are listed in Tables 3 and 4 , respectively.

The detection system consists of two $\mathrm{BF}_{3}$ tubes and six $\mathrm{NaI}$ detectors as shown in Figure 4.

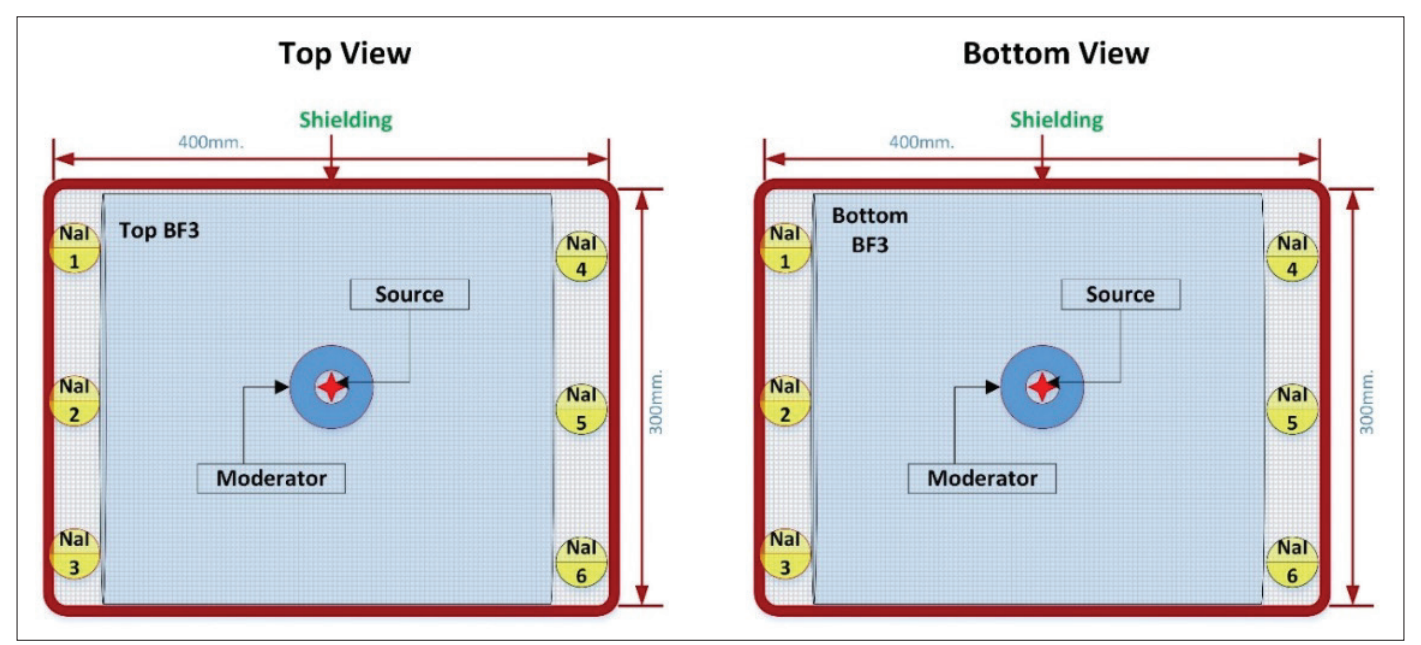

Figure 4: $\quad$ Model of EDS (XY plane) showing source, two $\mathrm{BF}_{3}$ detectors, and six NaI detectors 


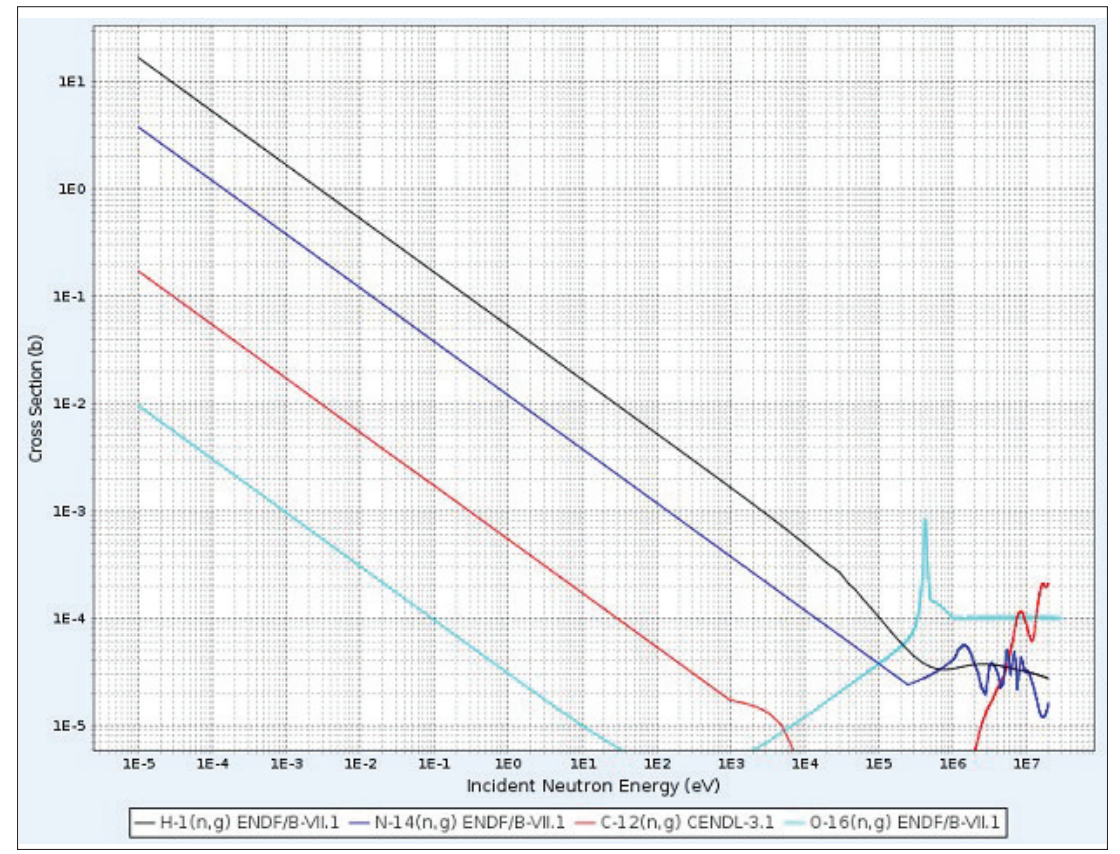

Figure 5: Neutron-induced cross-sections

Table 5: Gamma emissions from natural N

\begin{tabular}{lc}
\hline Energy $(\mathrm{keV})$ & \% intensity (rel) \\
\hline 1678.29 & 24.76 \\
1884.81 & 72.72 \\
2520.64 & 22.81 \\
3532.09 & 32.93 \\
4508.85 & 53.08 \\
5269.22 & 100.00 \\
5297.96 & 70.70 \\
5533.37 & 62.16 \\
5562.06 & 33.64 \\
6322.39 & 59.80 \\
7299.08 & 30.27 \\
10829.18 & 47.49 \\
\hline
\end{tabular}

\section{Design parameters}

The design parameters of a briefcase-fitted EDS are based on efficient sampling of the signatures of constituents of explosives resulting from their activation.

The gamma emissions from nitrogen are shown in Table 5. Two signature gamma rays are crucial for the detection and characterization of explosives viz

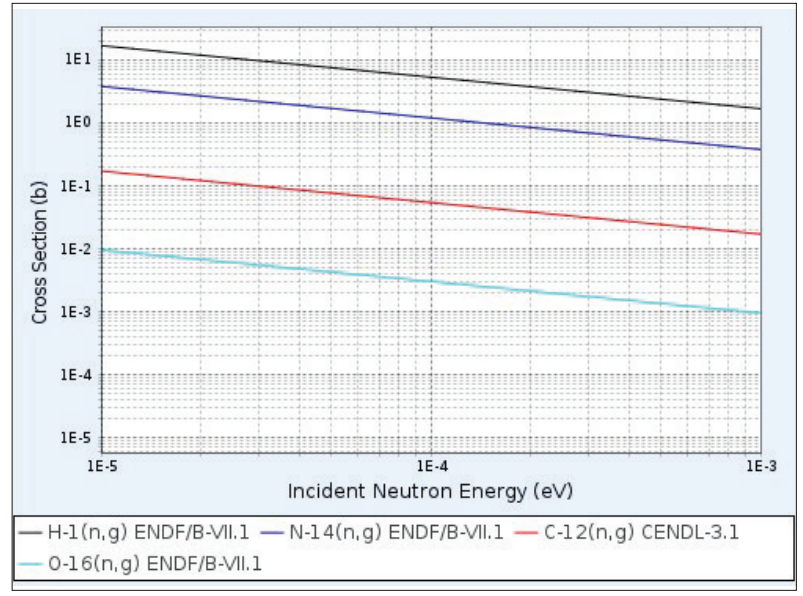

Figure 6: Neutron-induced $(n, \gamma)$ cross-sections at low energies

$10.829 \mathrm{MeV}$ emitted by $\mathrm{N}$ atoms and $2.2233 \mathrm{MeV}$ emitted from hydrogen.

As seen in Figure 5 (KAERI, 2019), the $(n, \gamma)$ crosssection is highest for $\mathrm{H}$, followed by $\mathrm{N}$, then $\mathrm{C}$ and finally O. For a smaller energy range, which is important for higher reaction rates, shown in Figure 6 (KAERI, 2019), it is seen that the ratios of $(n, \gamma)$ cross-sections become roughly constant. 


\section{RESULTS AND DISCUSSION}

All MCNP5 simulations with 10M histories were carried out on an Intel(R) Core(TM) i7-2620M CPU@2.70GHz 8GB RAM 32-bit operating system. The neutron crosssection data were used from Evaluated Nuclear Data Files (ENDF/B-VI) evaluated at $293.6 \mathrm{~K}$ with NJOY99.50 while photon cross-sections used ENDF/B-VI Release 8. The average source energy sampled was $2.3077 \mathrm{MeV}$. The simulation time was 12.01 minutes without a moderator and 15.54 minutes with the moderator.

Table 6: Volume of EDS and constituents (source, detection systems and moderator)

\begin{tabular}{lccccc}
\hline Item & Briefcase & Source & $\mathrm{BF}_{3}$ & $\mathrm{NaI}$ & Moderator \\
\hline $\begin{array}{l}\text { Volume } \\
\left(\mathrm{cm}^{3}\right)\end{array}$ & 9600.00 & 45.50 & 4396.00 & 452.16 & 4706.34 \\
\hline
\end{tabular}

In the first MCNP run, there was no moderator surrounding the $\mathrm{BF}_{3}$ tubes. Thus, at high energies, the mean free path $(\mathrm{mfp})$ in the tubes was $4.76 \times 10^{3} \mathrm{~cm}$, i.e. very few interactions. The average $\mathrm{mfp}$ in the upper BPE shield was $1.64 \mathrm{~cm}$ and in the lower BPE, it was $2.628 \mathrm{~cm}$. This difference arises due to the anisotropy of the source; the spectrum is harder and hence results in a longer mean free path. Similarly, for the upper $\mathrm{Pb}$ shield, the $\mathrm{mfp}$ is $\sim 4.15 \mathrm{~cm}$ and for the lower, it is $\sim 4.66 \mathrm{~cm}$. Thus, a sufficient number of interactions are expected at a thickness in the range of $3-4 \mathrm{~cm}$.

The volume of the EDS and constituents are listed in Table 6 . The total weight of the system, including the empty weight of briefcase $(2.5 \mathrm{~kg})$, is $10.7 \mathrm{~kg}$ of which the moderator weighs $4.33 \mathrm{~kg}$. The weights of electronics and power components such as power system, data acquisition, and accessories are not included in the present analysis.

It was found from the simulation that the main sources of photon production are from boron $(\bar{E} \sim 0.4792 \mathrm{MeV})$, lead $(\bar{E} \sim 1.24 \mathrm{MeV})$, calcium $(\bar{E} \sim 1.4626 \mathrm{MeV})$ in the limestone soil, hydrogen $(\bar{E} \sim 2.2368 \mathrm{MeV})$ in moderator and TNT explosive, carbon $(\bar{E} \sim 4.4420 \mathrm{MeV})$, nitrogen $(\bar{E} \sim 2.7828 \mathrm{MeV})$, oxygen $(\bar{E} \sim 4.5458 \mathrm{MeV})$, and iron $(\bar{E} \sim 1.1451 \mathrm{MeV})$. Essentially the simulations show that the EDS will receive large signals for three energy values i.e. $0.48 \mathrm{MeV}$ from boron $\left({ }^{10} \mathrm{~B}\right), 1.26 \mathrm{MeV}$ from lead $(\mathrm{Pb})$ and $1.46 \mathrm{MeV}$ from calcium.
Table 7: $\quad B(n, \alpha)$ reactions $\mathrm{cm}^{-3}$ per source $\mathrm{n}$ for $\mathrm{BF}_{3}$ detector volume $=2199.11 \mathrm{~cm}^{3}, \mathrm{~S}=6 \times 10^{7}(25 \mu \mathrm{g})$

\begin{tabular}{|c|c|c|c|}
\hline TNT (kg) & $\begin{array}{l}\text { PE Moderator } \\
\text { Mass (kg) }\end{array}$ & $\begin{array}{c}B(n, \alpha) \text { reactions/ } \\
\mathrm{cm}^{3} \text { per source } \mathrm{n} \\
\text { (relative error) }\end{array}$ & $\begin{array}{c}B(n, \alpha) \\
\text { reactions/s }\end{array}$ \\
\hline 1.03924 & nil & $\begin{array}{c}3.31273 \times 10^{-07} \\
(0.0103)\end{array}$ & 43710.35 \\
\hline nil & nil & $\begin{array}{c}1.22796 \times 10^{-07} \\
(0.0077)\end{array}$ & 16202.51 \\
\hline 1.03924 & 4.33 & $\begin{array}{c}8.25718 \times 10^{-06} \\
(0.0039)\end{array}$ & 108950.68 \\
\hline nil & 4.33 & $\begin{array}{c}7.24293 \times 10^{-06} \\
(0.0041)\end{array}$ & 95568.00 \\
\hline
\end{tabular}

The neutron flux in the $\mathrm{BF}_{3}$ with TNT was found to be $2.19 \times 10^{-4} \mathrm{~cm}^{-2}$ per source $\mathrm{n} / \mathrm{s}$ without a moderator and $2.38 \times 10^{-4} \mathrm{~cm}^{-2}$ per source $\mathrm{n} / \mathrm{s}$ with the moderator. Without TNT in the soil, the flux was $2.11 \times 10^{-4} \mathrm{~cm}^{-2}$ per source $\mathrm{n} / \mathrm{s}$ without a moderator and $2.35 \times 10^{-4} \mathrm{~cm}^{-2}$ per source $\mathrm{n} / \mathrm{s}$ with the moderator. An enhancement of $14 \%$ is thus estimated in the reaction rate as shown in Table 7 with and without TNT in a PE-moderated system. Without a moderator, the increase in counts was by a factor of $\sim 2.7$ but the signal was weaker by $\sim 40 \%$ due to neutron attenuation; this implies under-moderation but significant intensity attenuation of neutrons.

It is thus an under-moderated system; this is one of the disadvantages of placing the EDS in a briefcase as the required material would be $\sim 5-6 \mathrm{~cm}$ thick which is not available in the present design but can be used in a non-portable EDS. With this slight increase in flux, the efficiency of the $\mathrm{BF}_{3}$ tubes shows an increase to 0.018 .

The photon production in TNT is 20761 gammas per second, of which $\sim 12 \%$ are from $\mathrm{N}$ and $\sim 87 \%$ from $\mathrm{H}$. The neutron radiation dose in roentgen equivalent in man (rem) was found to be $1.215 \mathrm{rem} / \mathrm{h}$ without a moderator and $0.67 \mathrm{rem} / \mathrm{h}$ with the moderator. This is still far above the ICRP limit of $1 \mathrm{mrem} / \mathrm{h}$ and thus the system requires that the personnel handling should be adequately protected. The photon dose from neutrons, however, is $6.06 \mathrm{mrem} / \mathrm{h}$ with the moderator.

The reaction rates are defined as:

$R_{n, \gamma}=<N \sigma_{n, \gamma} \phi>$

where $\mathrm{N}$ is atomic number density (atoms $\mathrm{cm}^{-3}$ ), $R_{n, \gamma}$ 


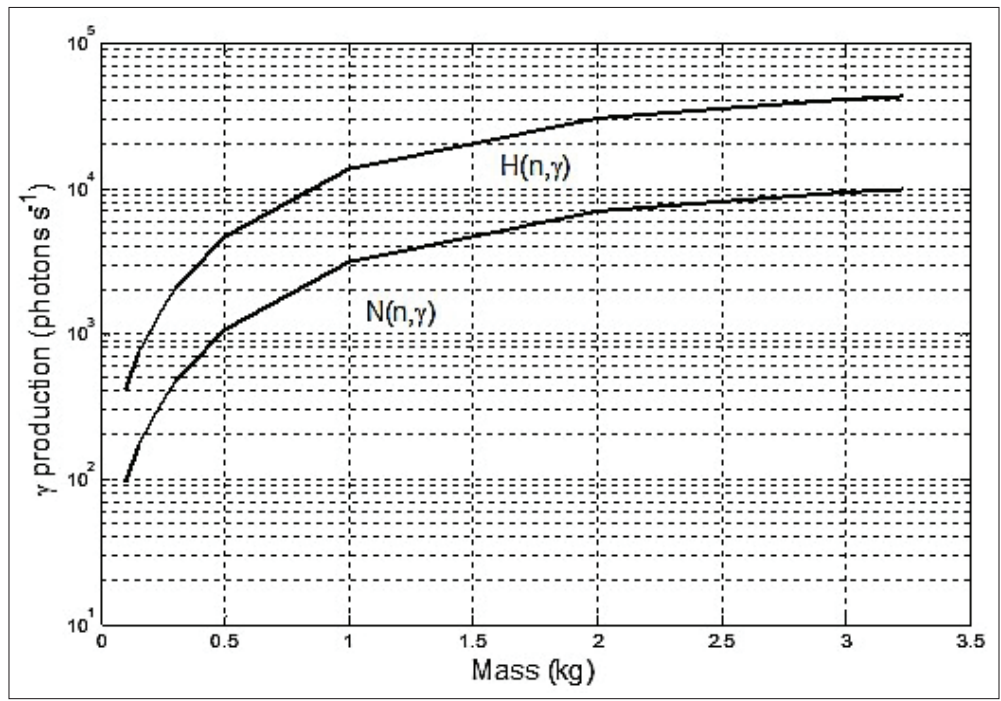

Figure 7: $\quad \gamma$ production rate from radiative capture $(\mathrm{n}, \gamma)$ in the explosive

is reaction rate for radiative capture $n, \gamma$ reactions, $\sigma_{n, \gamma}$ is microscopic cross sections for $n, \gamma$ reactions, and $\varnothing$ is neutron scalar flux.

so that the ratio $R_{n, \gamma}$ can be used to estimate the ratio of the atomic densities of two constituents, i.e.

$\frac{R_{n, \gamma}^{H}}{R_{n, \gamma}^{N}}=\frac{N^{H}}{N^{N}} \frac{\sigma_{n, \gamma}^{H}}{\sigma_{n, \gamma}^{N}} \sim C \frac{N^{H}}{N^{N}}$

where $C$ is roughly estimated from Figure 6. Further, the branching ratio is incorporated to account for gamma rays which can be emitted from nitrogen. Thus

$\frac{R_{n, \gamma}^{H}}{R_{n, \gamma}^{N}}=\frac{87}{12}=\frac{N^{H}}{N^{N}} \frac{\sigma_{n, \gamma}^{H}}{\sigma_{n, \gamma}^{N}} \sim C \frac{N^{H}}{N^{N}} \sim 4.5 \frac{N^{H}}{N^{N}}$

From which the atomic ratio is $\sim 1.61$ which is very close to the actual value for TNT (1.67). To get the signal from the TNT alone, it is necessary to obtain the signal strength with and without the TNT explosive.

The increase in gamma production, as a function of the mass of TNT, is as shown in Figure 7.

While gamma production is important, it is equally important to obtain a good signal from transmittance from the ground. As seen in Figure 8 the 'uncollided' 10.8 MeV gammas from nitrogen and 2.22 MeV gammas from hydrogen reduce steadily with soil thickness; at $5 \mathrm{~cm}$, for example, $\sim 70 \%$ of the $\mathrm{N}$ signal and $\sim 60 \%$ of

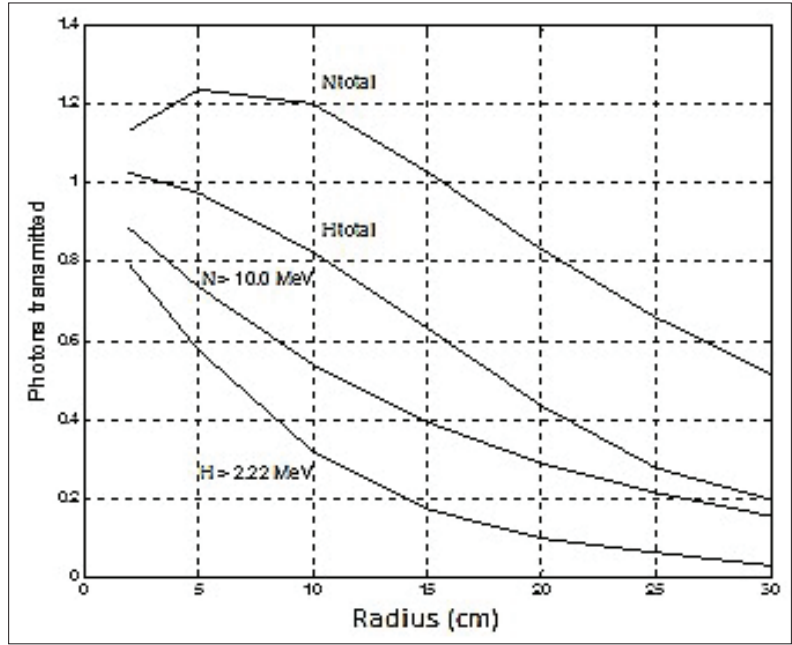

Figure 8: Comparison of 2.2233 $\mathrm{MeV}(\mathrm{H})$ photons and $10.8 \mathrm{MeV}$ photons $(\mathrm{N})$ transmitted across limestone

the $\mathrm{H}$ signal is transmitted. The total spectrum, counting all gammas is better; however, the spectrum becomes smeared.

The effect of source energy on the $(n, \gamma)$ reactions was examined by carrying out MNCP5 simulations for the model. For this purpose, a $\sim 140.3 \mathrm{~g}$ TNT explosive and source energy in the range $0.01-5 \mathrm{MeV}$ is considered. The TNT source used for these simulations is smaller 
than that considered for the earlier runs. The CPU time of $\sim 0.3$ minutes each was consumed and a relative standard error of less than $4 \%$ was achieved while simulating $10^{5}$ source neutrons.

Table 8: Radiative capture reactions from $\sim 140.3 \mathrm{~g}$ TNT $1 \mathrm{~cm}$ below ground in limestone

\begin{tabular}{|c|c|c|c|c|c|}
\hline Source Energy & $\mathrm{H}(\mathrm{n}, \gamma)$ & $\mathrm{C}(\mathrm{n}, \gamma)$ & $\mathrm{O}(\mathrm{n}, \gamma)$ & $\mathrm{N}(\mathrm{n}, \gamma)$ & Total \\
\hline $\mathrm{MeV}$ & \multicolumn{5}{|c|}{ Reactions $\mathrm{cm}^{-3}$ per source $\mathrm{n} / \mathrm{s}$} \\
\hline \multicolumn{6}{|l|}{ Mono-energetic source } \\
\hline 0.001 & $1.27126 \times 10^{-5}$ & $1.82070 \times 10^{-7}$ & $8.75284 \times 10^{-9}$ & $1.72269 \times 10^{-6}$ & $1.46262 \times 10^{-5}$ \\
\hline 0.01 & $1.28545 \times 10^{-6}$ & $1.83908 \times 10^{-8}$ & $8.84648 \times 10^{-10}$ & $1.74126 \times 10^{-7}$ & $1.47886 \times 10^{-6}$ \\
\hline 5.00 & $4.24581 \times 10^{-8}$ & $2.92567 \times 10^{-8}$ & $1.86949 \times 10^{-11}$ & $1.50811 \times 10^{-8}$ & $1.42674 \times 10^{-7}$ \\
\hline \multicolumn{6}{|c|}{ Am-Be $(E a v=4.5081)$ Source in cylinder $0.5 \mathrm{~cm}$ radius, height $1 \mathrm{~cm}($ for moderator, cylinder radius $=0.5 \mathrm{~cm}$, height $=4 \mathrm{~cm})$} \\
\hline No moderator & $1.33312 \times 10^{-7}$ & $3.69767 \times 10^{-8}$ & $9.18326 \times 10^{-11}$ & $3.03452 \times 10^{-8}$ & $2.00728 \times 10^{-7}$ \\
\hline Mod: PE den $=0.94$ & $5.63897 \times 10^{-8}$ & $2.22516 \times 10^{-8}$ & $3.76600 \times 10^{-11}$ & $1.42999 \times 10^{-8}$ & $9.29796 \times 10^{-8}$ \\
\hline \multicolumn{6}{|c|}{$252 \mathrm{Cf}(\mathrm{Eav}=2.3074)$ Source in cylinder $0.5 \mathrm{~cm}$ radius, height $1 \mathrm{~cm}$ (for moderator, cylinder radius $=0.5 \mathrm{~cm}$, height $=4 \mathrm{~cm})$} \\
\hline No moderator & $1.88805 \times 10^{-7}$ & $1.37931 \times 10^{-8}$ & $1.38145 \times 10^{-10}$ & $3.91033 \times 10^{-8}$ & $2.41841 \times 10^{-7}$ \\
\hline Mod: $\mathrm{PE}$ den $=0.94$ & $1.06942 \times 10^{-7}$ & $7.37392 \times 10^{-9}$ & $7.58959 \times 10^{-11}$ & $1.99804 \times 10^{-8}$ & $1.34373 \times 10^{-7}$ \\
\hline Mod: Pe den $=1.5$ & $9.73313 \times 10^{-8}$ & $5.45070 \times 10^{-9}$ & $6.83533 \times 10^{-11}$ & $1.66238 \times 10^{-8}$ & $1.19475 \times 10^{-7}$ \\
\hline
\end{tabular}

Table 9: reaction rate as a function of Pressure and ${ }^{10} \mathrm{~B}$ weight fraction in boron.

\begin{tabular}{lllll}
\hline $\begin{array}{l}\text { 10B in } \\
\text { Boron }\end{array}$ & $\begin{array}{l}\text { Gas density } \\
\mathrm{g} \mathrm{cm}^{-3}\end{array}$ & \multicolumn{3}{c}{$\mathrm{B}(n, \alpha)$ reactions $\mathrm{cm}^{-3}$ per source } \\
& & $\begin{array}{l}\mathrm{P}=1 \mathrm{~atm} \\
\text { neutron s }\end{array}$ & $\mathrm{P}=2 \mathrm{~atm}$ & $\mathrm{P}=3 \mathrm{~atm}$ \\
& & $\rho=\rho_{0}$ & $\rho=2 \rho_{0}$ & $\rho=3 \rho_{0}$ \\
\hline 0.2 & $2.7527 \times 10^{-3}$ & 1.15580 & 1.89182 & 2.41320 \\
0.5 & $2.7406 \times 10^{-3}$ & 2.16983 & 3.07464 & 3.57922 \\
0.9 & $2.7243 \times 10^{-3}$ & 3.89159 & 5.51797 & 6.42834 \\
\hline
\end{tabular}

The reaction rates, as source energy increases, are found to decrease by a factor of $\sim 100$ over the energy range considered. Thus, a low energy spectrum is highly advantageous for an EDS; ${ }^{252} \mathrm{Cf}$ source with an average energy 2.3074 $\mathrm{MeV}$ being superior to Am-Be source with an average energy $4.5081 \mathrm{MeV}$.

Thus, a decrease was observed in the reaction rate for both $\mathrm{Am}-\mathrm{Be}$ and ${ }^{252} \mathrm{Cf}$ sources, as shown in Table 8 for polyethylene (PE) densities of $0.9 \mathrm{~g} \mathrm{~cm}^{-3}$ and $1.5 \mathrm{~g} \mathrm{~cm}^{-3}$. This is due to the attenuation in the moderator, which reduces the intensity of the source radiation while 'softening' its spectrum. The overall effect is, however, not in favour of moderation, thus it is desirable to use a ${ }^{252} \mathrm{Cf}$ fast source spectrum for the EDS. As the density of the moderator is increased by $50 \%$, it is seen from the results that attenuation further decreases the reaction rate. It was observed that once the source energy was doubled from $5 \mathrm{MeV}$ to $10 \mathrm{MeV}$ (for cases where the source energy was in excess of $5 \mathrm{MeV}$ ), a trend reversal was observed as the $(n, \gamma)$ reaction cross-section starts to increase; for the $10 \mathrm{MeV}$ case the reaction rate was seen to increase two-fold from that of the $5 \mathrm{MeV}$ case.

Another parameter considered for enhanced performance was $\mathrm{BF}_{3}$ gas density in the detection system. MCNP5 simulations were carried out to estimate the reaction rate at $\mathrm{T}=300 \mathrm{~K}$ as a function of pressure

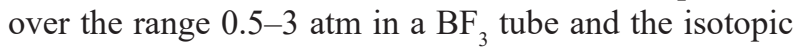
enrichment of ${ }^{10} \mathrm{~B}$. The results are shown in Table 9. It is seen that the reaction rate is best for highest boron enrichment in ${ }^{10} \mathrm{~B}$ and for highest gas pressure. Thus, it is desirable to operate with a high gas pressure as possible to maximize detection efficiency. However, achieving such operating conditions requires higher voltage, which is not desirable.

To ensure adequate shielding for ${ }^{252} \mathrm{Cf}$ source, for example, the neutron dose in vacuum at a distance of 1 $\mathrm{m}$ is $2.7083 \times 10^{-3} \mathrm{pSv}$ per source neutron $/ \mathrm{s}\left(1 \mathrm{pSv}=10^{-12}\right.$ $\mathrm{Sv})$ compared with the ICRP occupational limit $(20 \mathrm{mSv} /$ $\mathrm{y} \sim 1 \mathrm{mrem} / \mathrm{h}$ ) of $2.67 \mathrm{nSv} / \mathrm{s}$. One Sievert is equal to 100 rad (absorbed radiation dose). Thus, for a $25^{252} \mathrm{Cf}$ point source emitting $6 \times 10^{7} \mathrm{n} / \mathrm{s}$, the dose would be 16.25 $10^{4} \mathrm{pSv} / \mathrm{s}$ which is $\sim 60$ times the ICRP limit. Shielding 
design optimisation is thus a vital part of the design of any nuclear system, especially a portable EDS, which would require as strong a source as possible to get a good signal.

A $25 \mu \mathrm{g}{ }^{252} \mathrm{Cf}$ point source with $5 \mathrm{~cm}$ radius shields consisting of various materials were simulated to establish the radiation dose attenuation for each type of moderator. Simulation results for three-layer composite shields are shown in Figure 9. For a water shield, the neutron dose was found to be $6.75 \mathrm{rem} / \mathrm{h}$ while the photon dose is $5.87 \mathrm{mrem} / \mathrm{h}$. This compares with a SS316 shield giving a neutron dose $10.11 \mathrm{rem} / \mathrm{h}$ and a photon dose $0.0347 \mathrm{mrem} / \mathrm{h}$. It was found that the lowest neutron dose is from a polyethylene shield while $\mathrm{B}_{4} \mathrm{C}$ gives the lowest photon dose.

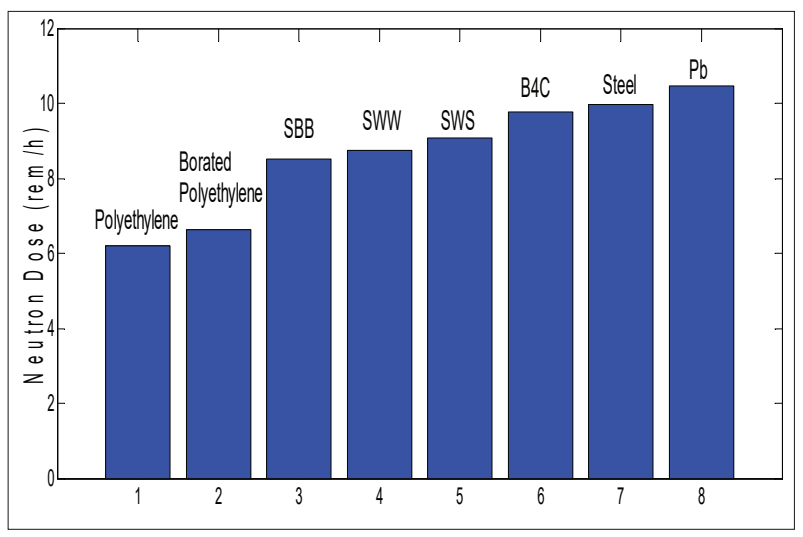

Figure 9: Neutron dose $(\mathrm{rem} / \mathrm{h})$ from a $5 \mathrm{~cm}$ thick shield (ICRP limit $\sim 1 \mathrm{mrem} / \mathrm{h}$ )

The neutron dose from the $5 \mathrm{~cm}$ shield needs to be reduced by a factor of 6000 to be within the ICRP limit on the occupational dose. Further, for a photon shield, gammas produced from low-Z shields can be reduced by using the borated polyethylene going up to $30 \%$ weight fraction boron. When the shield radius is increased from $5 \mathrm{~cm}$ to $15 \mathrm{~cm}$ of water, the neutron dose reduces from $6.75-0.385 \mathrm{rem} / \mathrm{h}$. At a radius of $45 \mathrm{~cm}$, the neutron dose reaches $1.325 \mathrm{mrem} / \mathrm{h}$ (relative standard error 0.1542 ) within the limit. MC simulation of such 'large' systems are considerably long, e.g. for wax moderator of $45 \mathrm{~cm}$ radius, the neutron dose was $0.53878(0.3407) \mathrm{mrem} / \mathrm{h}$ for the collided flux and $0.0294(0.0048) \mathrm{mrem} / \mathrm{h}$ for the collided flux for $25{ }^{252} \mathrm{Cf}$ point source which is well below the ICRP limit.
The simulation took 17.72 minutes for NPS $=1 \mathrm{M}$ neutrons simulated. The quality of the result also shows that variance reduction techniques may be required to improve the quality of the results. In such situations, MC perturbation is especially more relevant.

\section{CONCLUSIONS}

The design of a briefcase sized EDS was estimated with $25\left(6 \times 10^{7} \mathrm{n} / \mathrm{s}\right)$ encapsulated ${ }^{252} \mathrm{Cf}$ source in a steel casing shielded borated polyethylene and lead for neutron and photon shielding. Two $\mathrm{BF}_{3}$ and six $\mathrm{NaI}$ detectors were modelled. The briefcase was taken to be of dimensions $40 \mathrm{~cm} \times 30 \mathrm{~cm} \times 8 \mathrm{~cm}$ with a total filled weight of $\sim 10.7$ $\mathrm{kg}$ excluding electronics and accessories. It was shown that a significant neutron count signal was obtained for the detection of a TNT explosive weighing $1.039 \mathrm{~kg}$ concealed beneath the soil. The count rate showed a 14\% increase in the signal with and without the explosive. It was found that most of the photons were produced from ${ }^{10} \mathrm{~B}(\mathrm{E} \sim 0.48 \mathrm{MeV}), \mathrm{Ca}$ in limestone $(\mathrm{E} \sim 1.78 \mathrm{MeV})$, and $\mathrm{Pb}(\mathrm{E} \sim 1.24 \mathrm{MeV})$ in the shield. For photons, a strong signal of $2.22 \mathrm{MeV}$ photons from hydrogen was shown with the $\mathrm{H} / \mathrm{N}$ ratio suitable for identification of explosive. However, low energy photons from $\mathrm{N}$ were found with an average energy of $3.055 \mathrm{MeV}$.

Radiation shielding remains an area of concern for such a small-sized portable EDS and the neutron radiation was found to be well in excess of the ICRP limit of 1 $\mathrm{mrem} / \mathrm{h}$. Sufficient attenuation was found to be possible with $\sim 45 \mathrm{~cm}$ of polyethylene moderator followed by $\sim 3 \mathrm{~cm}$ of $\mathrm{Pb}$. However, the present design uses a good weight proportion of ${ }^{10} \mathrm{~B}(30 \%)$ in polyethylene so that low-energy photons $(\sim 0.4792 \mathrm{MeV})$ are shielded rather than from more hydrogenous moderator which would otherwise give $2.22 \mathrm{MeV}$ photons from hydrogen that would be more difficult to shield. The present EDS is sufficiently significant to be considered for a practical design when electronics and peripheral systems are also taken into account. Thus, further work is recommended to include the electronics system and its cooling mechanism as well as to consider the resolution of the detectors that is not included in the present analysis.

\section{REFERENCES}

Baysoy D.Y. \& Subaşı M. (2013). Numerical evaluation of a landmine detection system based on the neutron back scattering technique. Scientific Research and Essays 8(30): 1424-1430. 
Korea Atomic Energy Research Institute (KAERI) (2019). Nuclear Data Center, Korea Atomic Energy Research Institute, South Korea. Available at https: //atom.kaeri. re. $\mathrm{kr} /$, Accessed 24 June 2021.

Khan H., Koreshi Z.U. \& Yaqub M. (2017). The sensitivity studies of a landmine explosive detection system based on neutron back scattering using Monte Carlo simulation. Nuclear Technology and Radiation Protection 32(1): 37-43. DOI: https://doi.org/10.2298/NTRP1701037K

Koltick D. \& McConchie S. (2007). A neutron based vehicle borne improvised explosive device detection system. Proceedings of the $200741^{\text {st }}$ Annual IEEE International Carnahan Conference on Security Technology, Ottawa, Canada, pp. 292-300

DOI: https://doi.org/10.1109/CCST.2007.4373503

Koreshi Z.U. \& Khan H. (2016). Optimization of moderator design for explosive detection by thermal neutron activation using a genetic algorithm. Journal of Nuclear Engineering and Radiation Science 2(3): 031018-031018.

DOI: https://doi.org/10.1115/1.4032702

Koreshi Z.u. \& Khan H. (2017). Detector response from thermal neutron activation of concealed explosives. IIUM Engineering Journal 18(2): 177-188.

DOI: https://doi.org/10.31436/iiumej.v18i2.758

Kuznetsov A.V. \& Osetrov O.I. (2006). Detection of improvised explosives (IE) and explosive devices (IED). In: Detection and Disposal of Improvised Explosives, NATO Security through Science Series, pp. 7-25. Springer,
Dordrecht, Germany.

DOI: https://doi.org/10.1007/978-1-4020-4887-6_2

Lanza R.C. (2007). Chapter 6-neutron techniques for detection of explosives. In: Counterterrorist Detection Techniques of Explosives, pp. 131-155, Elsevier, Netherlands

DOI: https://doi.org/10.1016/B978-044452204-7/50025-0

Maučec M., \& De Meijer R.J. (2002). Monte Carlo simulations as a feasibility tool for non-metallic land-mine detection by thermal-neutron backscattering. Applied Radiation and Isotopes 56(6): 837-846.

DOI: https://doi.org/10.1016/S0969-8043(02)00064-7

Naqvi A.A., Kalakada Z., Al-Anezi M.S., Al-Matouq F., Maslehuddin M. \& Al-Amoudi O.S.B. (2014). Performance evaluation of a portable neutron generator for prompt gamma-ray applications. Arabian Journal for Science and Engineering 39(1): 531-539.

DOI: https://doi.org/10.1007/s13369-013-0880-y

Team M.C. (2003). MCNP - Version 5, volume I: Overview and Theory, LA-UR-03-1987. Available at https://mcnp. lanl.gov/mcnp faq.shtml

Uchai W., Changkian S., Zhu L. \& Sun H. (2008). Experiment on the performance of the neutron-based explosives detection system using 252Cf and 241Am/9Be. Suranaree Journal of Science and Technology 15(2): 139-147.

Whetstone Z.D. \& Kearfott K.J. (2014). A review of conventional explosives detection using active neutron interrogation. Journal of Radioanalytical and Nuclear Chemistry 301(3): 629-639.

DOI: https://doi.org/10.1007/s10967-014-3260-5 